\title{
Phytochemical Screening of Pentadesma butyracea Sabine (Clusiaceae) Acclimated in Benin by GC/MS
}

\author{
J. P. A. Noudogbessi, ${ }^{1}$ A. K. Natta, ${ }^{2}$ F. P. Tchobo, ${ }^{1}$ G. S. Bogninou, ${ }^{1}$ F. T. D. Bothon, ${ }^{1}$ \\ A. D. Bossou, ${ }^{1}$ G. Figueredo, ${ }^{3}$ P. Chalard, ${ }^{4}$ J. C. Chalchat, ${ }^{5}$ and D. C. K. Sohounhloué ${ }^{1}$ \\ ${ }^{1}$ Laboratoire d'Etude et de Recherche en Chimie Appliquée (LERCA), Ecole Polytechnique d'Abomey-Calavi, \\ 01 BP 2009 Cotonou, Benin \\ ${ }^{2}$ Faculté d'Agronomie, Laboratoire d'Etudes et de Recherches Forestières (LERF), Université de Parakou, BP 123 Parakou, Benin \\ ${ }^{3}$ Laboratoire d'Analyse des Extraits Végétaux et des Arômes (LEXVA Analytique), 460 rue du Montant, 63110 Beaumont, France \\ ${ }^{4}$ Institut de Chimie de Clermont-Ferrand (ICCF), Ecole Nationale Supérieure de Chimie de Clermont-Ferrand (ENSCCF), BP 10448, \\ 63000 Clermont-Ferrand, France \\ ${ }^{5}$ Laboratoire de Chimie des Huiles Essentielles, Université Blaise-Pascal, (Clermont-Ferrand II), Campus des Cézeaux, \\ 63177 Aubière Cedex, France
}

Correspondence should be addressed to D. C. K. Sohounhloué; csohoun@gmail.com

Received 27 December 2012; Accepted 27 January 2013

Academic Editors: R. K. Jyothi, T. Macko, and W. X. Misiuk

\begin{abstract}
Copyright (C) 2013 J. P. A. Noudogbessi et al. This is an open access article distributed under the Creative Commons Attribution License, which permits unrestricted use, distribution, and reproduction in any medium, provided the original work is properly cited.

The results brought back at the end of this work concerned various chemical constituents of $P$. butyracea materials collected in seven forest galleries in northern of Benin. The phytochemical analysis showed mucilage, coumarins, gallic tannins, flavones, sterols, and saponins, in its leaves. The cyclohexanic fractions realized from petroleum ether extracts and analysed by GC/MS were marked by important rates of 9, 19-cyclolanost-24-en-3 $\beta$-3-ol (49.3-72.6\%), taraxasterol (18.4-30.1\%), and friedooleanan-3one (10.0\%). Essential oils extracted by hydrodistillation from $P$. butyracea and analyzed by GC/MS contained 11 to 38 compounds representing 85.2 to $99.5 \%$ of the weight of this volatile extracts essentially rich in sesquiterpene constituents. The essential oils predominant compounds $(>10 \%)$ identified and recorded independently of the organ studied were $\beta$-caryophyllene (14.9-77.9\%), aromadendrene (43.5\%), $\alpha$-copaene (18.4-26.6\%), $\alpha$-ylangene (21.1\%), germacrene-B (5.1-13.5\%), selina-3,7(11)-diene (13.3\%), $\alpha$ humulene (6-13.3\%), (2E, $6 \mathrm{Z})$ - $\alpha$-farnesene (12.6\%), seychellene (12.0\%), and palmitic acid $(10,6 \%)$.
\end{abstract}

\section{Introduction}

The food forest tree species were plentiful in African forest ecosystems, and they contributed to the household economy, to the strengthening food security, and to the preservation of the biological diversity of forest resources [1]. In Benin, some of these woody species including $P$. butyracea were threatened with a severe extinction due to the lack of a real program of long-lasting management of their ecosystems [2]. $P$. butyracea is a dense forest species with a distribution area reaching from Sierra Leone to the Cameroun [3]; it is a tree, with a height of about $20 \mathrm{~m}$, which was found in the north of Benin in forest galleries and along water way [4]. The bark, rough, and deeply cracked exudes a thick resinous juice, of reddish yellow color. The leaves were $10-22 \mathrm{~cm}$ long, $3.5-7 \mathrm{~cm}$ broad, with numerous close parallel, lateral nerves; the flowers were large, white, or sometimes red-dish; the fruits were broadly ellipsoid, pointed, about $15 \mathrm{~cm}$ long and $10 \mathrm{~cm}$ large [5]; they contained oleaginous almonds which were consumed like kola [6] and were used to extract an edible butter (named kanga or lamy butter) [7], similar to Shea butter (Butyrospermum parkii Katschy, Sapotaceae). P. butyracea butter was used in traditional medicine as massage oil, in skin and hair care, and in the manufacture of soap for its softening, lubricating, and healing qualities [8]. It was used to retard the ageing of skin in patented cosmetic preparation [9]. In Gabon, the macerated bark was used in lotions for the treatment of the parasitic diseases of the skin and as 
antidiarrheal [10]. In Ghana, the roots decoction was used to fight intestinal worms [11]. The social and economic value of this plant species made it a known tree and potentially used for multiple purposes. Indeed, its organs (almonds, leaves, flowers, bark, and roots) were used in food, cosmetic, and therapeutic practices $[6,11]$. Previously, the chemical investigations realized by Alitonou et al. showed that the essential oils extracted from leaves, bark, and roots of $P$. butyracea harvested to Natitingou in Benin contained high levels of hydrogenated sesquiterpenes, mainly dominated by the $\beta$-caryophyllene (58-75\%) [12]. In 2007, Tchobo et al. reported that the content of stearic and oleic acids in butter extracted from P. butyracea seeds were $96.0 \%$. They also signified the presence of this butter of sterols (68.0\%) whose predominants were stigmasterol and $\beta$-tocopherol [13]. This work was thus a contribution to the recovery of this species (Pentadesma butyracea Sabine (Clusiaceae)) endangered in Benin by the highlighted thanks to modern technical and appropriate analysis of the chemical constituents, possibly bioactive. It also aims to verify if $P$. butyracea was chemically constant in each of its parts taken by studying the volatile compounds extracted from its various parts resulting from several localities of Benin.

\section{Experimental}

2.1. Plant Material, Oil Isolation, and Obtaining Powders. The $P$. butyracea vegetal materials were collected in June-July 2006 in the forest galleries of Agbassa, Bakabaka, Bassila, Natitingou-Ville, Penelan, and Penessoulou situated in the northern of Benin. They were authenticated at the National Herbarium of Abomey-Calavi University. In the laboratory, these materials were kept between 18 and $20^{\circ} \mathrm{C}$ in the shade of sunlight throughout the study period. The essential oils were obtained in pentane from $750 \mathrm{~g}$ of leaves, trunk bark, roots, and root bark by using hydrodistillation technic during $8 \mathrm{~h}$ with a Clevenger (Type Apparatus), according to the British pharmacopoeia method [14]. The pentane was evaporated at ambient temperature. They were dried over anhydrous sodium sulfate and analyzed by GC/FID and GC/MS. For the determination of nonvolatile compounds, powders were obtained from the leaves, dried in the dark for one month, by grinding with a knives machine Ika Werke MF 10 basic type. Vegetable powders collected are then sieved in the size grading 0.425 .

2.2. Nonvolatile Constituent Identification of P. butyracea Leaves. The phytochemical screening was made according to the standard techniques described by Paris and Moyse [15], Bouquet [16], Debray et al. [17], and Harborne [18].

Mucilages. $1 \mathrm{~mL}$ of decoction realized previously was treated with $5 \mathrm{~mL}$ of absolute ethanol, and the presence of mucilage was noticed by the appearance of a flaky precipitate.

Coumarins. An infusion was made from $10 \mathrm{~g}$ of powder and $100 \mathrm{~mL}$ of ethanol. The alcoholic extract obtained was examined under UV light $(365 \mathrm{~nm})$. The appearance of a bluish fluorescence indicated a positive reaction.

Tannins Gallic. An aqueous infusion was prepared from $5 \mathrm{~g}$ of plant powder and $100 \mathrm{~mL}$ of boiling distilled water. After $15 \mathrm{~min}$, the mixture was filtered. The residue was rinsed with hot water to bring the volume of the filtrate to $100 \mathrm{~mL}$. $20 \mathrm{~mL}$ of the filtrate is saturated with sprayed sodium sulfate, and then, it was added dropwise $1 \mathrm{~mL}$ of ferric chloride (1\%). The development of a blue-black tint corresponded to the presence of gallic tannins, not precipitated by Stiasny's reagent.

Flavones. They were introduced in a test tube, $5 \mathrm{~mL}$ of the infused. In this content, $5 \mathrm{~mL}$ of hydrochloric alcohol constituted by equal volumes of ethanol at $95^{\circ}$, distilled water, concentrated hydrochloric acid (37\%), and $1 \mathrm{~mL}$ of isoamylic alcohol was added. In the presence of shavings magnesium, it emerged at the supernatant layer (layer isoamyl alcohol) a pink-orangey color indicating the presence of genins of flavonoids.

Leucoanthocyanins. They were identified by being introduced into a test tube $5 \mathrm{~mL}$ of infused (5\%) and $5 \mathrm{~mL}$ of hydrochloric (ethanol $95^{\circ}+$ distilled water + hydrochloric acid $37 \%$ of equal volumes). The mixture was competed with $1 \mathrm{~mL}$ of isoamylic alcohol and then heated to $90^{\circ}$ through a water bath. After fifteen minutes, it had developed a red-cerise tint (or purple) indicating the presence of leucoanthocyanins.

Saponins. A decoction was prepared during $30 \mathrm{~min}$ from two grams of plant powder and $100 \mathrm{~mL}$ of distilled water. After filtering the obtained mixture, the filtrate was divided into 10 different volumes $(1 \mathrm{~mL}, 2 \mathrm{~mL}, 3 \mathrm{~mL}$, and $10 \mathrm{~mL})$ in 10 calibrated tubes (internal diameter $: 1.3 \mathrm{~cm}$ ). The content of each tube was adjusted to $10 \mathrm{~mL}$ with distilled water. After shaking each tube in a horizontal position for 15 seconds, followed by a rest of $15 \mathrm{~min}$ in an upright position, the height of the foam supernatant was measured in $\mathrm{cm}$. When this height is close to $1 \mathrm{~cm}$ in the $X$ th tube, the foam index $(I)$ is calculated by the following formula: $\mathrm{I}=$ foam height $(\mathrm{in} \mathrm{cm}$ ) in the $X$ th tube $\times 5 / 0.0 X$. The presence of saponins in the plant is confirmed when the value of the foam index is greater than 100 .

Sterols and Triterpenes (Liebermann-Burchard Test). It was proceeded to the depigmentation of $100 \mathrm{mg}$ of powder hydroalcoholic extract of $P$. butyracea with $10 \mathrm{~mL}$ of cyclohexane under hanging excitement for $5 \mathrm{~min}$. The depigmented residue is then treated with $10 \mathrm{~mL}$ of chloroform. The recovered solution, dried over sodium sulfate anhydrous, was filtered, and the filtrate obtained was divided into two test tubes. In the first tube, were introduced three drops of acetic anhydride. After gentle stirring, it was added a drop of concentrated sulfuric acid. One hour later, the appearance of a blue-green color indicates the presence of steroids or triterpenes if it changes from red-purple to pink. In the second tube, no color change was observed.

Free Anthraquinones. They were carried out with $1 \mathrm{~g}$ of plant material powder and $10 \mathrm{~mL}$ of chloroform. Afterward, $1 \mathrm{~mL}$ of the extract filtrate was shaken with $1 \mathrm{~mL}$ of $\mathrm{NH}_{4} \mathrm{OH}$ diluted 
TABLE 1: Chemical families identified in P. butyracea leaves.

\begin{tabular}{cccccccc}
\hline Mucilage & Free antraquinones & Coumarin & $\begin{array}{c}\text { Gallic } \\
\text { tannins }\end{array}$ & Flavones & Leucoanthocyanines & $\begin{array}{c}\text { Saponins } \\
\text { (foam index })\end{array}$ & $\begin{array}{c}\text { Sterols and } \\
\text { triterpenes }\end{array}$ \\
\hline+++ & + & +++ & +++ & ++ & + & $++(50.0)$ & ++ \\
\hline
\end{tabular}

+++: abundant; ++: average; +: very little.

TABLE 2: Chemical composition of unsaponifiable extracts of $P$. butyracea organs.

\begin{tabular}{|c|c|c|c|c|c|}
\hline \multirow{2}{*}{ Compounds } & \multirow{2}{*}{ KI } & $\mathrm{L}$ & $\mathrm{TB}$ & $\mathrm{R}$ & $\mathrm{RB}$ \\
\hline & & \multicolumn{4}{|c|}{$\%$} \\
\hline$\alpha$-cubebene & 1351 & - & 0.1 & 0.1 & 0.1 \\
\hline$\alpha$-copaene & 1380 & 4.3 & 0.2 & 0.2 & 0.1 \\
\hline cyperene & 1411 & - & - & 0.7 & 0.2 \\
\hline$\beta$-caryophyllene & 1425 & 0.4 & 6.9 & 7.8 & 4.4 \\
\hline trans- $\alpha$-bergamotene & 1438 & - & - & 0.1 & - \\
\hline allo-aromadendrene & 1464 & - & 1.1 & 1.3 & 0.8 \\
\hline$\alpha$-selinene & 1491 & 0.4 & - & 0.1 & - \\
\hline$\beta$-bisabolene & 1512 & - & 0.3 & 0.3 & 0.2 \\
\hline$\delta$-cadinene & 1522 & 0.7 & 0.1 & 0.1 & 0.1 \\
\hline Caryolan-8-ol & 1584 & - & - & 0.1 & - \\
\hline Caryophyllene oxide & 1590 & - & 0.2 & 0.1 & 0.1 \\
\hline 6,10,14-trimethylpentadecan-2-one & 1837 & 1.2 & - & - & - \\
\hline Phytol & 1949 & 8.5 & - & - & - \\
\hline Dibutyl phthalate & 2142 & - & 0.2 & 0.2 & - \\
\hline Cyclododecane & 2469 & - & - & - & 0.2 \\
\hline cis-octadec-13-enal & 2475 & - & - & - & 0.2 \\
\hline squalene & 2824 & 2.6 & 0.1 & - & - \\
\hline nonacosane & 2878 & 3.7 & - & - & - \\
\hline$\beta$-tocopherol & 3028 & 0.5 & - & - & - \\
\hline$\gamma$-tocopherol & 3036 & 0.6 & - & - & - \\
\hline Hentriacontane & 3099 & 3.3 & - & - & - \\
\hline$\alpha$-tocopherol & 3118 & 1.0 & - & - & - \\
\hline$\delta$-5-ergosterol & 3204 & 0.6 & - & - & - \\
\hline Lanosta-8,24-dien-3 $\beta$-3-ol & 3231 & 1.7 & 0.8 & 1.3 & 0.4 \\
\hline 9,19-cyclolanost-24-en-3 $\beta$-3-ol & 3260 & 49.3 & 55.0 & 54.7 & 72.6 \\
\hline Hop-22(29)-en-3 $\beta$-ol & 3328 & 2.6 & - & - & - \\
\hline 9,19-cyclolanost-23-en-3 $\beta$-3,25-diol & 3332 & 2.6 & - & - & - \\
\hline Lupeol & 3338 & - & 2.6 & - & - \\
\hline Friedooleanan-3-one & 3432 & 10.0 & - & - & - \\
\hline 3-oxo-friedooleanan-28-al & 3672 & 0.7 & - & - & - \\
\hline Taraxasterol & 3386 & - & 30.1 & 21.3 & 18.4 \\
\hline Lup-20(29)-ene-3,28-3 $\beta$-diol & 3680 & - & 0.5 & - & - \\
\hline Total & & 94.7 & 98.2 & 88.4 & 97.8 \\
\hline
\end{tabular}

L: leaves, TB: trunk barks, R: roots, RB: root barks, KI: kovats index.

to $50 \%$. A more or less intense coloration indicating the presence of the free anthraquinones was observed.

2.3. P. butyracea Fatty Acids (FA) and Unsaponifiable (Un) Identification. Lipids Extraction. $15.0 \mathrm{~g}$ of the vegetable material powder was twice extracted successively by $100 \mathrm{~mL}$ of petroleum ether $\left(40-60^{\circ} \mathrm{C}\right)$ with magnetic stirring at room temperature. After filtration and evaporation of the solvent under reduced pressure, the extracts were dried and weighed.
The yields were established in calculating the average of three extractions.

Saponification and Fatty Acids Obtention. The saponification was conducted by refluxing, during thirty minutes past one oclock, $0.5 \mathrm{~g}$ of plant extract, and $25 \mathrm{~mL}$ of an ethanolic and potassium hydroxide solution $(2 \mathrm{~N})$. After cooling, $50 \mathrm{~mL}$ of water was added and the unsaponifiable matter is extracted by $3 \times 50 \mathrm{~mL}$ of cyclohexane. The soap solution produced was 


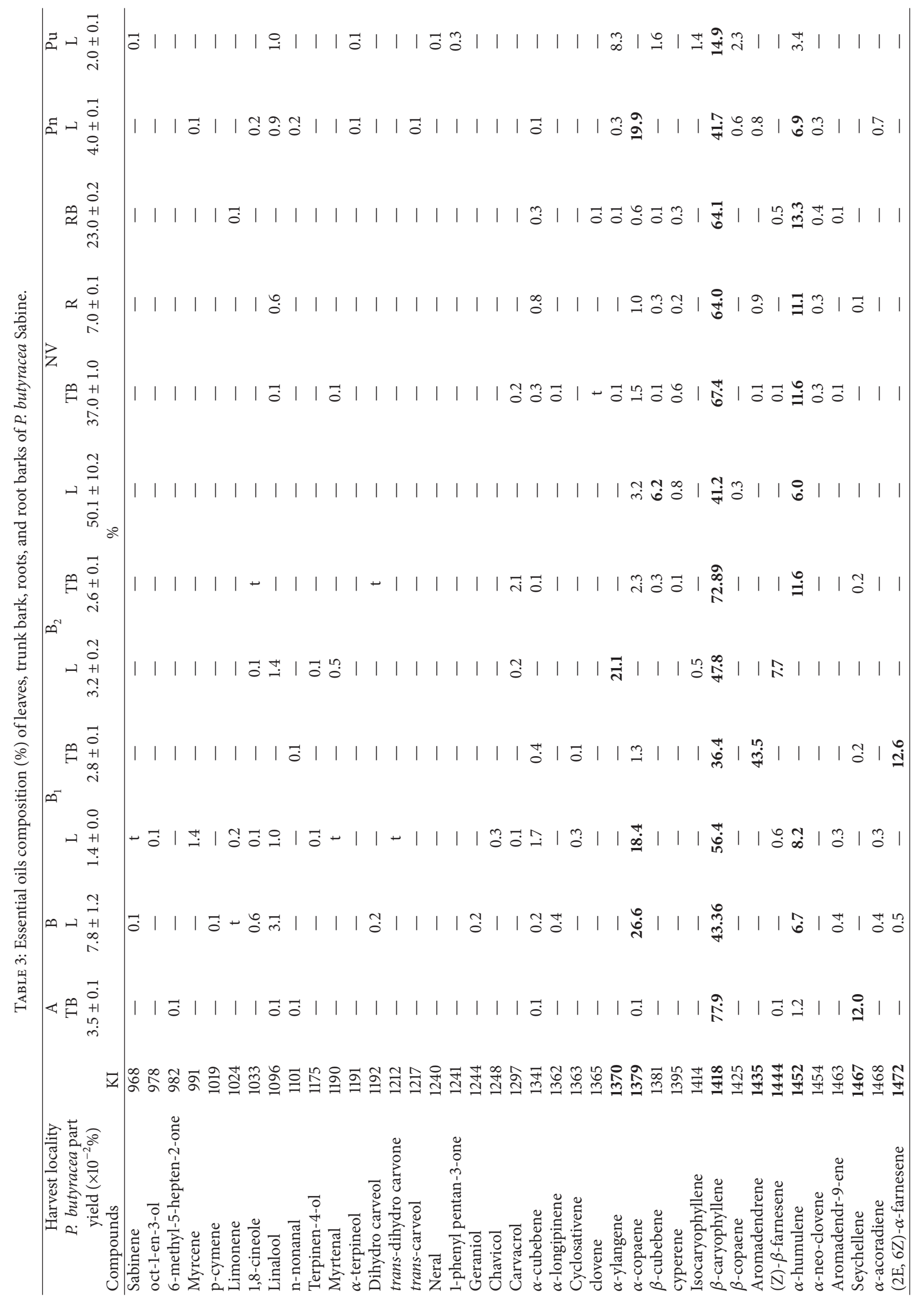




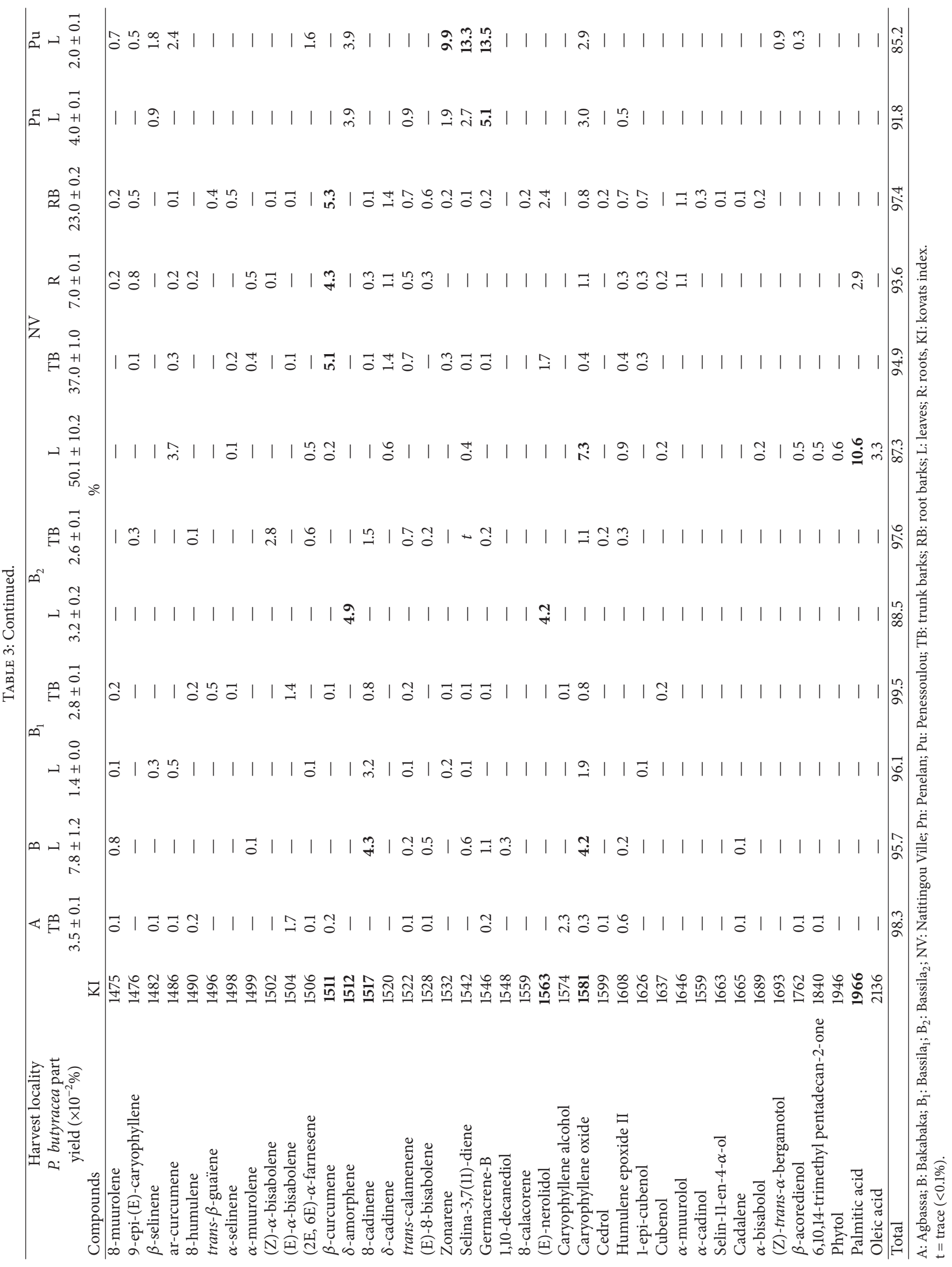


then acidified to precipitate the FA $(5 \leq \mathrm{pH} \leq 6)$. The FA released was yet extracted by $3 \times 50 \mathrm{~mL}$ of diethyl ether [19, 20].

FA Methylation. Fatty acids were converted to their methylic esters by addition a methanolic solution $(10 \%)$ of boron trifluoride $\left(\mathrm{BF}_{3}\right)$, and the methylic esters were extracted with cyclohexane.

The analysis of FA and Un collected was made through GC/FID and GC/MS [21].

2.4. GC/FID and GC/MS Analysis. The essential oils were analyzed on a Hewlett-Packard gas chromatograph Model 5890, coupled with a Hewlett-Packard MS model 5871, equipped with a DB5 MS column $(30 \mathrm{~m} \times 0.25 \mathrm{~mm}, 0.25 \mu \mathrm{m})$, programming from $50^{\circ} \mathrm{C}(5 \mathrm{~min})$ to $300^{\circ} \mathrm{C}$ at $5^{\circ} \mathrm{C} / \mathrm{mn}, 5 \mathrm{~min}$ hold. Helium as carrier gas $(1.0 \mathrm{~mL} / \mathrm{min})$; injection in split mode (1:30); injector and detector temperature, 280 and $280^{\circ} \mathrm{C}$ respectively. The MS works in electron impact mode at $70 \mathrm{eV}$; electronmultiplier: $2500 \mathrm{eV}$; ion source temperature: $180^{\circ} \mathrm{C}$; mass spectra data were acquired in the scan mode in $\mathrm{m} / \mathrm{z}$ range 33-450. The essential oil was analysed on a Hewlett-Packard gas chromatograph Model 6890, equipped with a DB5 MS column $(30 \mathrm{~m} \times 0.25 \mathrm{~mm}, 0.25 \mu \mathrm{m})$, programming from $50^{\circ} \mathrm{C}(5 \mathrm{~min})$ to $300^{\circ} \mathrm{C}$ at $5^{\circ} \mathrm{C} / \mathrm{mn}, 5 \mathrm{~min}$ hold. Hydrogen as carrier gas $(1.0 \mathrm{~mL} / \mathrm{min})$; injection in split mode (1:60); injector and detector temperature, 280 and $300^{\circ} \mathrm{C}$ respectively. The essential oil is diluted in hexane: 1/30.

The compounds found by GC in the different essential oils were identified by comparing their retention indices with those of reference compounds in the literature. Their identities were further confirmed using GC/MS and comparing their mass spectra with those of reference substances [22-26].

\section{Results and Discussion}

The characterization tests showed that the mucilages, coumarins, and gallic tannins were the groups of compounds abundantly identified in the P. butyracea leaves (Table 1 ). Low levels of flavones, sterols, and triterpenes then saponins (foam index $=50.0$ ) were also revealed in that leaves.

The fatty acids proportion, determined with regard to the mass of dry vegetable material, varied from 0.3 to $1.3 \%$. These values were very low compared to that which has been identified in Vetiveria zizanioïdes (31.3\%) by Champagnat [27]. Also, the unsaponifiables rates of the different parts of P. butyracea ranged between 0.7 and $1.6 \%$. It was noted in the leaves an unsaponifiable rates similar to that reported by Dencausse (1.5\%) in 1995 after extracting P. butyracea butter unsaponifiables [8]. The roots, leaves, and barks of $P$. butyracea were characterized by a not interesting chemical composition in fatty acids. Indeed, the proportions of fatty acids obtained were very low $(<0.2 \%)$. In the leaves, it was noted the presence of fatty acids such as palmitic $(0.16 \%)$, oleic $(0.1 \%)$, arachidic $(0.1 \%)$, and linoleic $(0.1 \%)$ acids, whereas $P$. butyracea roots were only characterized by the tricosanoic acid $(0.1 \%)$. In the roots, no fatty acid was identified. The unsaponifiable fractions extracted from $P$. butyracea organs contained 13 to 20 compounds distributed between $55.8 \%$ and $73.0 \%$ of sterols and $10.7 \%-33.2 \%$ of triterpenes (Table 2).

The main sterol common to all the parts of the $P$. butyracea tree was 9,19-cyclolanost-24-en-3 $\beta$-3-ol (49.3 to $72.6 \%$ ) (Table 2). The taraxasterol percentages appeared in the trunk bark, the roots, and the root barks were, respectively, 30.1, 21.3 and $18.4 \%$. The sterols identified in these organs were different from those identified by Tchobo et al. in P. butyracea seeds unsaponifiables. In fact, the major sterol identified in P. butyracea butter by Tchobo et al. was stigmasterol estimated to $68.0 \%$ [13]. This difference would denote the inhomogeneity of the chemical constituents that may arise between the various parts of a plant. The leaves were specifically constituted by the other compounds in particular friedooleanan-3-one (10.0\%), phytol (8.5\%), nonacosane (3.7\%), hentriacontane $(3.3 \%)$, and squalene $(2.6 \%)$. Some terpenic compounds remarkable by their percentages were also identified in the different parts of $P$. butyracea. These were, firstly, the $\beta$-caryophyllene (4.4-7.8\% in the roots) and secondly the $\alpha$-copaene ( $4.3 \%$ in the leaves). It is necessary to indicate that the nonacosane and the hentriacontane were two hydrocarbons saturated usual of the vegetable kingdom [27], having each an odd number of carbon atoms. P. butyracea was one of the many non ligneous forest products which leaves, barks, and roots have an aromatic character with a producing power of essential oils. The pursuit of the chemical constituent investigations of this plant species was also made by extracting essential oils from $P$. butyracea different parts collected in several forests of the northern region of Benin. The yields of essential oils, which ranged from $50.10 \times 10^{-2} \%$ to $1.41 \times 10^{-2} \%$, were the averages of three runs (Table 3 ).

The results (Table 3 ) showed that the essential oils from leaves, bark, and roots of $P$. butyracea have constituted mainly by hydrocarbons sesquiterpene (56.2-98.2\%). Comparatively to sesquiterpene hydrocarbons, the oxygenated sesquiterpene was very poorly represented in these volatile extracts $(1.2-9.5 \%)$. These volatile extracts were also low in volatile oxygenated $(\leq 4.1 \%)$ and hydrocarbon $(0.0-$ $1.6 \%)$ monoterpenes. These sesquiterpenoids compounds predominance would result from the metabolic reactions inside the vegetable from which the precursors were farnesyl pyrophosphate isomers $(2 \mathrm{Z}, 6 \mathrm{E})$ and $(2 \mathrm{E}, 6 \mathrm{E})$ [28]. Eleven and thirty-eight compounds, representing $85.2 \%$ to $99.5 \%$ of the total weight of the essential oils, have been identified independently of the investigated portion of the shaft. The major substance present in all the essential oils samples, in amounts according to the organ origin, was $\alpha$ caryophyllene (14.9-77.9\%). Other major compounds were noted: $\alpha$-aromadendrene (43.5\%), copaene (18.4-26.6\%), $\alpha$ ylangene $(21.1 \%), \alpha$-copaene $(19.9 \%), \alpha$-humulene $(6.0-$ $13.3 \%),(2 \mathrm{E}, 6 \mathrm{Z})-\alpha$-farnesene (12.6\%), seychellene (12.0\%), $\beta$-cubebene (6.2\%), palmitic acid (10.6\%), selina-3,7(11)diene $(13.3 \%)$, germacrene-B (5.1-13.5\%), zonarene (9.9\%), caryophyllene oxide (4.2-7.3\%), $\beta$-curcumene $(4.3-5.3 \%)$, $\delta$-amorphene $(4.9 \%), 8$-cadinene $(4.3 \%)$, and (E)-nerolidol (4.2\%). Although all samples of $P$. butyracea studied during 
the current works have been collected in the north of Benin characterized by the same climate (Sudano-Guinean), the rates in $\beta$-caryophyllene stemming from the chemical profiles obtained from analysis by GC/MS performed varied from one region to another then according to each every treated organ (Table 3). The explanation for this situation could probably denote of the influence of the soil nature of the different regions of harvest and the plant vegetative state at the date of the diverse crops. So according to the chemical profile of the P. butyracea essential oil targeted to NV, the rate in $\beta$-caryophyllene of roots $(64.0 \%)$ is closed to that of the barks and of the roots (64.1\%), but these values were slightly lower than the $\beta$-caryophyllene percentage of TB (67.4\%) of the same tree. The only tree of $P$. butyracea whose leaves have produced an interesting rate of $\beta$-caryophyllene $(56.4 \%)$ resulted from $B_{1}$. This value was well below the one that brought back from P. butyracea leaves essential oil of Natitingou (58.0\%) in 2010 [12]. The lowest proportion of $\beta$ caryophyllene (14.9\%) was recorded in the volatile extract of $P$. butyracea leaves harvested in $\mathrm{Pu}$. It is necessary to notice that only the barks collected at B1 contained a high rate of aromadendrene (43.5\%), while $\alpha$-ylangene (21.1\%), (2E, 6Z)$\alpha$-farnesene (12.6\%), seychellene (12.0\%), and palmitic acid (10.6\%) really characterized the volatile extracts from leaves harvested, respectively in $\mathrm{B}_{2}, \mathrm{~B}_{1}$, and $\mathrm{A}$ in Benin.

\section{Conclusion}

In view of the obtained results, it appears that $P$. butyracea, beyond the strong content fat of its seeds and its potential exploitation for the manufacturing of the butter was a big source (spring) of the other metabolites. The phytochemical investigations realized by using appropriate solvents showed in the $P$. butyracea leaves the presence of instrong proportion of coumarins, tannins gallic, mucilages, 9.19-cyclolanost-24en-3 $\beta$-3-ol, taraxasterol, and fatty acids tracks. The essential oil of this plant is potentially rich in sesquiterpenes hydrogenated, in particular $\beta$-caryophyllene appeared in all the parts of the vegetable species. Further investigation on a larger number of individuals collected on the explored sites and somewhere else in Benin will allow highlighting essential chemotypes at $P$. butyracea Sabine volatile extract.

\section{References}

[1] P. Vantomme, "FAO: activités relatives aux produits forestiers non ligneux," OBIT, Actualités des Forêts Tropicales, vol. 7, pp. 25-33, 1999.

[2] J. Z. Dah-Dovonon, "Espèces ligneuses alimentaires in réseau," in Compte Rendu de La Première Réunion du Réseau, CNSF, Ouagadougou, Burkina Faso, 2000.

[3] A. Natta, R. Sogbégnon, and F. Tchobo, "Connaissances endogènes et importance du Pentadesma butyracea (Clusiaceae) pour les populations autochtones au Nord-Ouest Bénin," Fruit, Vegetable and Cereal Science and Biotechnology, vol. 4, pp. 18-25, 2010.

[4] A. K. Natta, Ecological assessment of riparian forests in Benin: Phytodiversity, phytosociology and spatial distribution of tree species [Ph.D. thesis], University of Wageningen, Wageningen, The Netherlands, 2003.

[5] J. Hutchinson and J. M. Dalziel, Flora of West Tropical Africa, vol. 1, part 1, 2nd edition, 1954.

[6] B. Sinsin and A. T. Sinadouwirou, "Valorisation socioéconomique et pérennité du Pentadesma butyraceae Sabine en galeries forestières au Bénin," Cahier D'études et de Recherches Francophones /Agriculture, vol. 12, pp. 75-79, 2003.

[7] D. J. Mabberley, The Plant-Book, Cambridge University Press, Cambridge, UK, 1987.

[8] L. Dencausse, H. Ntsourankoua, J. Artaud, and J. L. Clamou, "Comparaison des compositions lipidiques des beurres de Pentadesma butyracea et de Karité," Oléagineux, Corps Gras, Lipides, vol. 2, no. 2, pp. 143-147, 1995.

[9] O. Courtin, "Cosmetic preparation to retard the ageing skin," European Patent Applications., p. 13, 1986.

[10] A. Raponda-Walker and R. Sillans, Les Plantes Utiles du Gabon, Paul Lechevalier, Paris, France, 1961.

[11] D. K. Abbiw, "Useful plants of Ghana," in Intermadiate Tecnology Publications and the Royal Botanic Gardens Kew, London, UK, 1990.

[12] G. Alitonou, F. Avlessi, D. C. K. Sohounhloue, J. M. Bessière, and C. Menut, "Chemical and biological investigation on volatile constituents of pentadesma butyracea sabine (clusiaceae) from Benin," Journal of Essential Oil Research, vol. 22, no. 2, pp. 138140, 2010.

[13] F. P. Tchobo, A. K. Natta, B. Barea et al., "Characterization of pentadesma butyracea sabine butters of different production regions in Benin," Journal of the American Oil Chemists' Society, vol. 84, no. 8, pp. 755-760, 2007.

[14] British Pharmacopoeia, 11. P. A. HMSO, London, UK, 1980.

[15] R. Paris and H. Moyse, Précis De Matière Médicinale, Masson, Paris, France, 1969.

[16] M. Bouquet, Travaux et Documents de L'Orstom, Paris, France, 1971.

[17] M. Debray, H. Jacquemin, and R. Razafindrambo, Travaux et Documents de L'Orstom, Paris, France, 1971.

[18] J. B. Harborne, Phytochemical Methods: A Guide to Modern Techniques of Plant Analysis, Chapman and Hall, New York, NY, USA, 1973.

[19] D. Joulain and W. Konig, The Atlas of Spectral Data of Sesquiterpene Hydrocarbons, E. B., Hamburg, Germany, 1998.

[20] J. P. Wolff, Manuel d'Analyse des Corps Gras, Azoulay, Paris, France, 1968.

[21] L. D. Metcalfe and A. A. Schmitz, "The rapid preparation of fatty acid esters for gas chromatographic analysis," Analytical Chemistry, vol. 33, no. 3, pp. 363-364, 1961.

[22] P. Rösch, J. Popp, and W. Kiefer, "Raman and SERS investigations on lamiaceae," Journal of Molecular Structure, vol. 121, pp. 480-481, 1999.

[23] R. P. Adams, Identification of Essential Oils Components By Gas Chromatography/ Mass Spectrometry, Allured Publishing Corporation, Carol Stream, Ill, USA, 1995.

[24] W. Jennings and T. Shibamoto, Quantitative Analysis of Flavor Volatiles By Gas Capillary Chromatography, Academic Press, New York, NY, USA, 1980.

[25] N. W. Davies, "Gas chromatographic retention indices of monoterpenes and sesquiterpenes on methyl silicone and Carbowax 20M phases," Journal of Chromatography, vol. 503, no. 1, pp. 1-24, 1990. 
[26] L. Doimo, R. J. Fletcher, and B. R. D’Arcy, “Comparison in the $\gamma$-lactone content of oils and extracts from white cypress pine (Callitris glaucophylla Thompson \& Johnson)," Journal of Essential Oil Research, vol. 11, no. 4, pp. 415-422, 1999.

[27] P. Champagnat, Etude phytochimique sur les Poaceae: analyses de Vetiveria zizanoïdes et de Vetiveria nigritana, recherche de quelques activités biologiques [Ph.D. thesis], Université d'Auvergne, 2007.

[28] J. Mann, Secondary Metabolism, Clarendon Press, Oxford, UK, 2nd edition, 1987. 

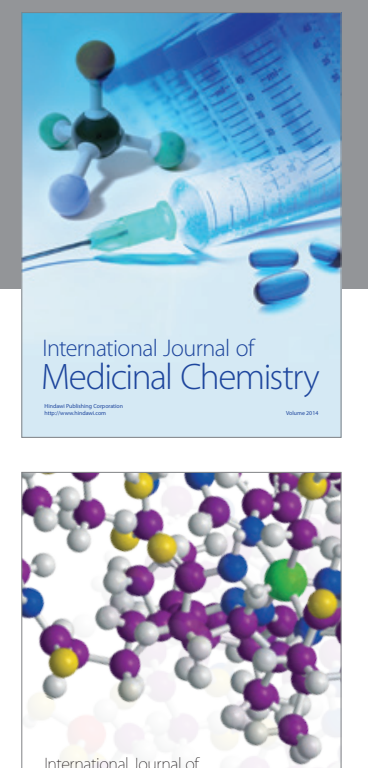

\section{Carbohydrate} Chemistry

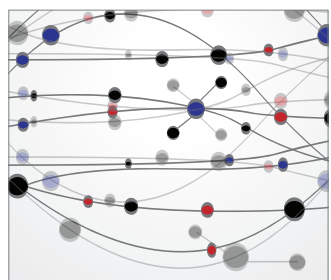

The Scientific World Journal
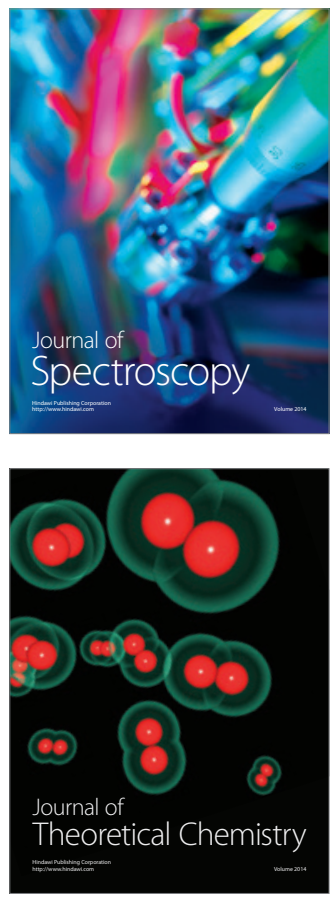
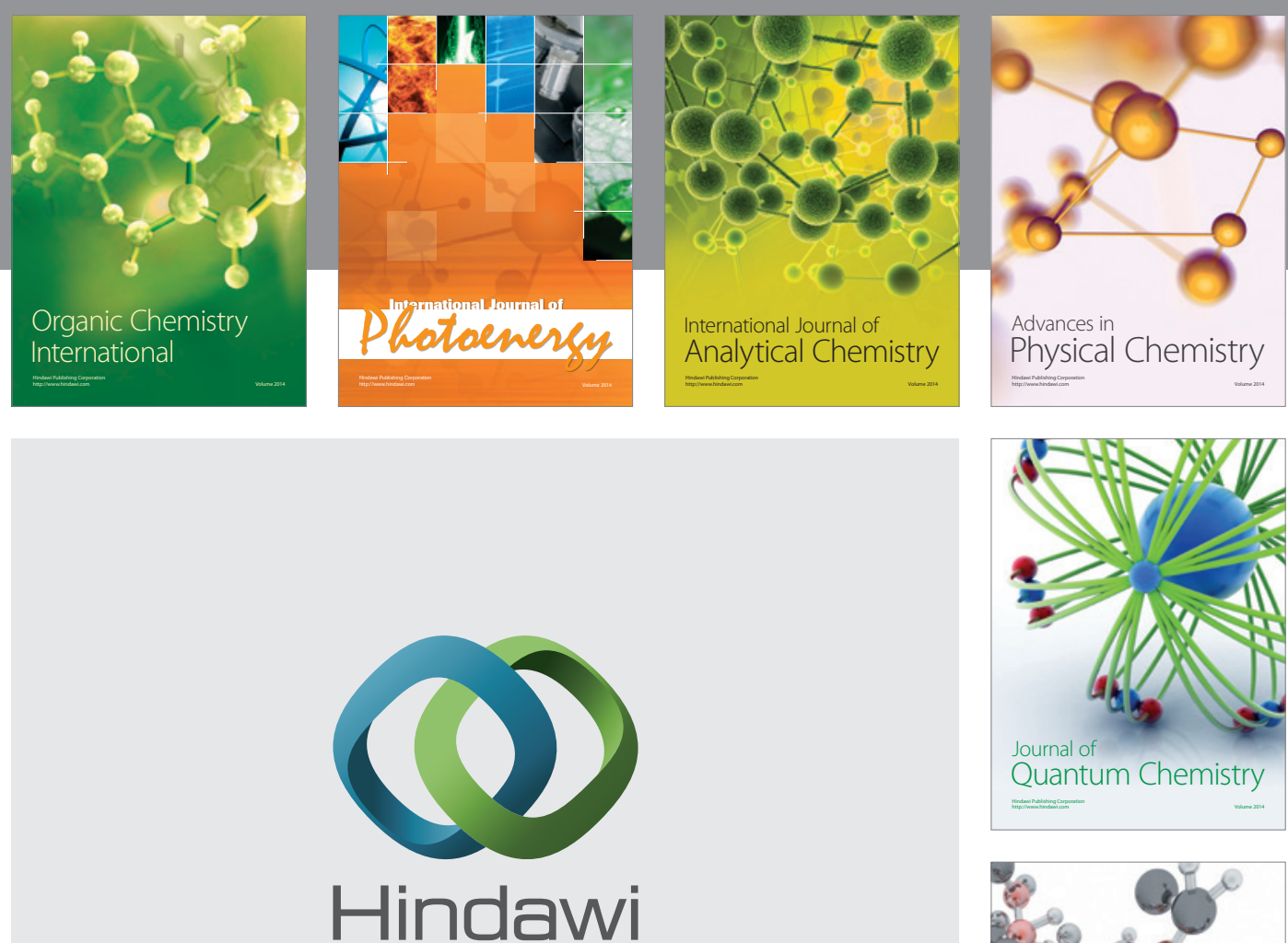

Submit your manuscripts at

http://www.hindawi.com

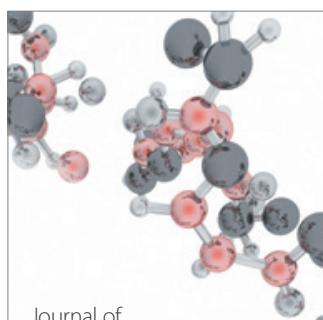

Analytical Methods

in Chemistry

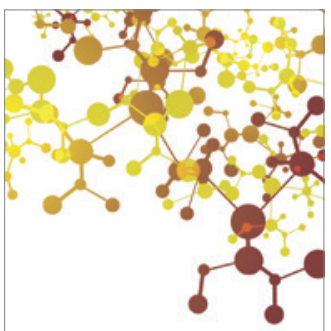

Journal of

Applied Chemistry

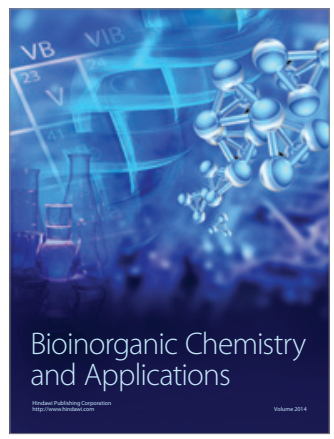

Inorganic Chemistry
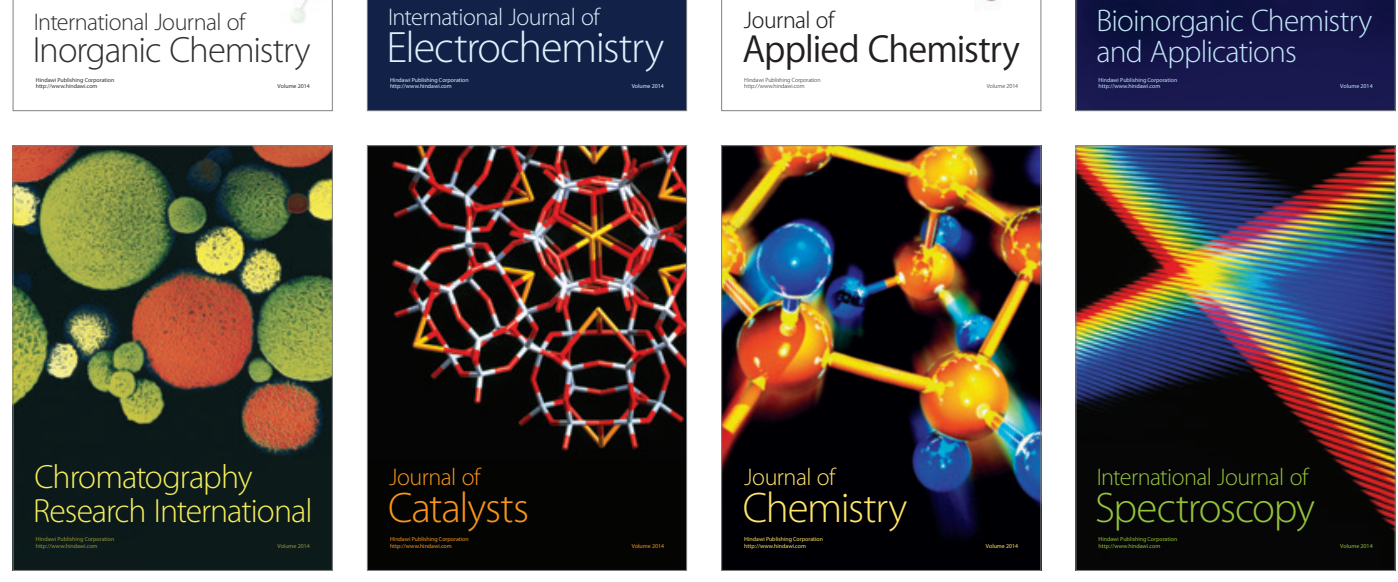